Revue belge de géographie

4 | 2004

Maritime and port economic geography

\title{
Bruneau M. (2004), Diasporas et espaces \\ transnationaux
}

Paris, Anthropos- Economica, collection Villes-Géographie

\section{Julien Vandeburie}

\section{(2) OpenEdition}

\section{Journals}

\section{Édition électronique}

URL : http://journals.openedition.org/belgeo/13470

ISSN : 2294-9135

Éditeur :

National Committee of Geography of Belgium, Société Royale Belge de Géographie

Édition imprimée

Date de publication : 31 décembre 2004

Pagination : 497-508

ISSN : 1377-2368

\section{Référence électronique}

Julien Vandeburie, «Bruneau M. (2004), Diasporas et espaces transnationaux », Belgeo [En ligne], 4 | 2004, mis en ligne le 15 septembre 2013, consulté le 22 septembre 2020. URL : http:// journals.openedition.org/belgeo/13470

Ce document a été généré automatiquement le 22 septembre 2020.

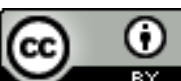

Belgeo est mis à disposition selon les termes de la licence Creative Commons Attribution 4.0 International. 


\title{
Bruneau M. (2004), Diasporas et espaces transnationaux
}

\author{
Paris, Anthropos- Economica, collection Villes-Géographie
}

Julien Vandeburie

\section{RÉFÉRENCE}

Bruneau M., Diasporas et espaces transnationaux, Paris, Anthropos- Economica, collection Villes-Géographie, 2004

1 La nouvelle collection d'Anthropos s'enrichit d'un nouvel ouvrage très intéressant. En effet, la question des diasporas, souvent évoquée (par l'exemple, l'Atlas des diasporas de Chaliand et Rageau, 1991) est finalement rarement traitée de manière aussi systématique que dans cet ouvrage.

2 L'auteur s'attache d'abord à définir ce qu'il entend par diaspora. Dans ce premier chapitre, on discute de la définition mais aussi de la position épistémologique d'une étude des diasporas. Quelle est sa place parmi les sciences sociales, parmi la géographie ? Il propose également une bonne réflexion sur les types de cartographie à adapter. La formation, les types de diasporas sont envisagées.

3 Dans un deuxième temps, M. Bruneau détaille les liens familiaux, communautaires et religieux à l'origine de l'iconographie qui fonde une diaspora. Les cas des Juifs, des Grecs, des Arméniens et des Antillais, dans leurs ressemblances et différences, sont abordés.

Dans un troisième chapitre, il est question des liens entre les diasporas et les constructions politiques : peuple, nation et Etat-Nation. Bruneau se pose la question de ce qu'est un peuple en diaspora, est-ce qu'il s'agit d'une nation? et pose l'intéressante question d'une diaspora noire, issue entre autres de la traite. Les exemples juif, grec, arménien, indien et chinois sont ensuite confrontés. 
5 Tandis que le chapitre IV explore les désastres à l'origine des diasporas en évoquant la question de la mémoire ; le chapitre $\mathrm{V}$ s'attaque à dénouer les liens entre les diasporas, les migrations de main-d'œuvre et les réseaux entrepreneuriaux. Les cas des diasporas marchandes, pionnières, commerciales, de main-d'œuvre (plantations, etc.) sont envisagés. Les exemples des Noirs, Libanais, Indiens, Chinois, Grecs mais aussi de la structuration du commerce « ethnique ».

6 Dans le chapitre VI, l'auteur construit les fondations d'une réflexion sur l'espace des diasporas, ainsi peut-on parler d'espaces transnationaux? On aurait envie de dire oui. Les exemples juif, tsigane, les modèles des trois peuples-mondes (grec, indien, chinois) sont très séduisants ainsi que l'exemple turc, et forment la partie la plus intéressante de l'ouvrage. Même si ceci avait déjà été évoqué par l'auteur dans plusieurs de ses articles, l'apport est riche.

7 Finalement, l'auteur change d'échelle et examine, trop rapidement, ce qu'il intitule « Villes, cosmopolitisme, ségrégations et diasporas». De bonnes idées mais un développement un peu court précèdent la conclusion du livre.

8 Un ouvrage riche, intéressant, une excellente base pour étudier les diasporas sous un angle géographique, voilà comment on pourrait résumer le livre de M. Bruneau. 